\title{
Multidetector computed tomography in orthostatic proteinuria?
}

\author{
Gregorio P. Milani • Marta B. M. Mazzoni • \\ Emilio F. Fossali • Mario G. Bianchetti
}

Received: 5 March 2010 /Accepted: 23 March 2010 /Published online: 13 April 2010

(C) IPNA 2010

Sirs,

Orthostatic proteinuria is a condition characterized by increased protein excretion in the upright position, but normal protein excretion in the supine position, which affects up to $5 \%$ of adolescents [1]. Anecdotal observations suggest that orthostatic proteinuria might sometimes reflect incipient renal disease. However, most authoritative reports state that this condition is benign, with renal function remaining normal after as long as 50 years' follow-up. Furthermore, orthostatic proteinuria resolves spontaneously in most patients, being present in about $50 \%$ at 10 years and $20 \%$ at 20 years [1].

In most subjects with this form of proteinuria, renal ultrasound imaging and Doppler flow scanning reveal entrapment of the left renal vein in the fork between the abdominal aorta and the proximal superior mesenteric artery close to its origin. It has been therefore postulated that partial obstruction to the flow in the left renal vein in the upright position alters glomerular microcirculation, thus leading to increased protein filtration $[2,3]$.

Very recently, Cho et al. evaluated children and adolescents with orthostatic proteinuria by means of multidetector computed tomography and noted that both the angle and the distance between the aorta and the superior

G. P. Milani • M. B. M. Mazzoni • E. F. Fossali

Emergency Unit, Clinica Pediatrica De Marchi,

Foundation IRCCS Ca' Granda Ospedale Maggiore Policlinico, Milan, Italy

\section{G. Bianchetti $(\bowtie)$}

Department of Pediatrics, Mendrisio and Bellinzona Hospitals, University of Bern,

Bern, Switzerland

e-mail: mario.bianchetti@pediatrician.ch mesenteric artery were significantly altered in subjects with postural proteinuria [3]. The sophisticated imaging studies of the report further support left renal vein entrapment in the pathogenesis of isolated orthostatic proteinuria.

The lifetime cancer mortality risks attributable to radiation from a computed tomography examination are considerably higher for children than for adults. It has been estimated that the lifetime cancer mortality risk attributable to the radiation exposure from a single abdominal computed tomography examination in a 1-year-old child is approximately one in 500 [4].

Considering the cancer mortality risk attributable to radiation from an abdominal computed tomography, the benign nature of postural proteinuria, and its spontaneous resolution, we strongly advise against the use of multidetector computed tomography in postural proteinuria, as suggested by Cho et al. [3]. No imaging studies or renal ultrasound imaging and Doppler flow scanning are currently performed at our institutions in children with isolated postural proteinuria.

\section{References}

1. Omoloja AA, Patel H, Ey E, Jackson E (2007) Common renal problems in pediatric medicine. Curr Probl Pediatr Adolesc Health Care 37:153-194

2. Ragazzi M, Milani G, Edefonti A, Burdick L, Bianchetti MG, Fossali EF (2008) Left renal vein entrapment: a frequent feature in children with postural proteinuria. Pediatr Nephrol 23:1837-1839

3. Cho BS, Suh JS, Hahn WH, Kim SD, Lim JW (2010) Multidetector computed tomography findings and correlations with proteinuria in nutcracker syndrome. Pediatr Nephrol 25:469-475

4. Bertell R, Ehrle LH, Schmitz-Feuerhake I (2007) Pediatric CT research elevates public health concerns: low-dose radiation issues are highly politicized. Int J Health Serv 37:419-439 